\title{
Serum Immunoglobulins in Children with Vitamin D Resistant Rickets
}

\author{
Ezzat K. Amin', Hossam Kamal', Ahmed M. Gab-Allah², Seham A. Alzarrouq ${ }^{3}$ \\ and Mohamed A. Talat ${ }^{*}$
}

${ }^{1}$ Department of Pediatrics, Zagazig University, Egypt, ${ }^{2}$ Department of Clinical pathology and, ${ }^{3}$ Department of Pediatrics, Tarablus University hospital, Libya

\begin{abstract}
Background: Vitamin D plays an immunoregulatory role in both the innate and adaptive immune systems. Rickets is a disorder that can develop due to a lack of vitamin D, calcium, or phosphate. Aim: The aim of this study was to assess serum immunoglobulins as one of the aspects of humoral immunity in children with vitamin D resistant rickets. Subjects and Methods: This casecontrol study was performed on 60 patients divided into Group (A):30 cases with vitamin D resistant rickets patients who were presented with rachitic manifestation who did not respond to therapeutic doses of the vitamin. Group (B):30 cases with untreated classic vitamin D deficiency rickets. Group (C): 30 healthy subjects as a control group. All subjects were subjected to detailed history taking including age, sex, weight, dietary history, medication history, and physical examination including vital signs, body weight, and head circumference. Laboratory investigations that included calcium, phosphorus, alkaline phosphatase, electrolytes, ESR, urine analysis, parathyroid hormone, vitamin $\mathrm{D}$, and Immunoglobulin assay. Results: There is a significant decrease of IgA in vitamin $D$ deficiency rickets and vitamin $D$ resistant rickets than in controls $(3.74$ $\pm .867,3.13 \pm 1.72,5.01 \pm 1.61$, respectively with $P=0.012)$. There is a significant decrease of IgG in vitamin $D$ deficiency rickets and a significant increase in vitamin $D$ resistant rickets than in controls $(523.5 \pm 136.3,751.25 \pm 163.5,692.0 \pm 186.4$, respectively with $P=0.009)$. There is no significant difference in IgM in the three studied groups. Conclusion: Patients with vitamin $D$ deficiency have significantly lower IgG levels, while vitamin D resistant patients have significantly higher IgG levels. Whereas, both groups have lower IgA and normal IgM levels.
\end{abstract}

Key words: 25-hydroxyvitamin D, Calcium, Phosphorus, PTH, vitamin D receptor gene.

\section{Introduction}

Rickets is a condition that results in weak or soft bones in children. Symptoms include bone pain, stunted growth, large forehead, bowed legs, and trouble sleeping. Complications may include bone fractures, abnormally curved spine, muscle spasms and intellectual disability ${ }^{(1)}$. Vitamin $D$ resistant rickets is defined by its resistance to the vitamin $D$ treatment generally used in deficiency rickets. 
Typical signs are observed from the first months of life: radiological signs of defective mineralization on cartilage growth plates (rickets) and bone (osteomalacia) and alterations of phosphocalcic homeostasis in spite of a satisfactory vitamin D status. The clinical phenotype combines bone deformities, mainly at the lower limbs, and other signs depending upon the etiology of the resistance. Vitamin D-resistant rickets is the common clinical outcome of multiple genetic mutations that alter the regulation of phosphorus and vitamin D metabolism, mainly through their effects on fibroblast growth factor 23 (FGF-23). These diseases typically present in childhood with the classic physical examination finding of nutritional rickets, such as genu varum/valgum and rachitic rosary ${ }^{(2)}$. Immunoglobulins are glycoprotein molecules that are produced by plasma cells in response to an immunogen. The immunoglobulins are divided into 5 different classes, based on differences in the amino acid sequences in the constant region of the heavy chains(3). The discovery of vitamin $D$ receptors (VDR) in every cell showed that a vitamin $D$ a role in immunomodulation as activation of the VDR by $1,25 D$ alters cytokine secretion patterns, suppresses effector $\mathrm{T}$ cell activation and induces regulatory $T$ cells ( tolerance action). Also, 1,25D can enhance the phagocytic activity of macrophages and increase the activity of natural killer cells promoting defense immunity (innate immune response). Therefore, tissue and cell specific differences in the regulation of $25 \mathrm{D}$ are highly relevant to the roles of 25D and 1,25D as immunomodulators ${ }^{(4)}$. Recently, a connection between nutritional rickets and a decrease in the function of the immune system was investigated. Children with nutritional rickets were more susceptible to respiratory infection than those that had a normal level of serum vitamin D (5). Unfortunately, there are little study data about immunoglobulins in vitamin $D$ resistant or deficiency rickets. Therefore, we aimed to assess serum immunoglobulins as one of aspects of humeral immunity in children with vitamin $D$ resistant rickets.

\section{Subjects and Methods}

\section{Study Sample}

This case-control study was performed at pediatric department of our university hospital in the period from June 2018 to March 2019. Consent have been gotten from the parents of the patients involved in the study as suggested by the Institutional Ethical Committee of our university and in accordance with the Helsinki declaration after a full clarification of the reason and nature of all procedures used. Sixty patients and were included in this study were divided into: Group (A): 30 cases with vitamin $D$ resistant rickets patients who were presented with rachitic manifestation who did not respond to therapeutic doses of vitamin D: 10 cases with vitamin $D$ dependent rickets type I (VDDR type 1) \& 9 cases with vitamin D dependent rickets type 2 (VDDR type 2) \& 11 cases with hypophosphatemic rickets. Group (B): thirty cases with untreated classic vitamin $D$ deficiency rickets. Group (C): thirty healthy subjects as a control group. Patients with hepatic or renal disorders, patients with vitamin D deficiency secondary to use of chronic use of medications e.g. antiepileptic drugs and patients with immunodeficiency (congenital $\&$ acquired) were excluded from the study.

\section{Study Methods}

All subjects were subjected to detailed history taking including age, sex, weight, dietary history, and medication history. Clinical and physical examination including vital signs, body weight and head circum- 
ference. Laboratory investigations that included $A$ - Routine investigations including; 1) Complete blood count (CBC) were performed on Sysmex-Kx-21 (Sysmex Corporation -Japan); 2) Kidney function tests: blood urea nitrogen (BUN, mg/dl), creatinine $(\mathrm{mg} / \mathrm{dl})$ and liver function: aspartate aminotransferase (AST, IU/I), alanine aminotransferase (ALT, IU/I) tests, calcium, phosphorus and alkaline phosphatase on (Cobas Integra 400 plus, Roche, Germany) ;3) Electrolytes; Na, K, Mg 4) ESR; 5) Urine analysis 6) Parathyroid hormone (PTH) \&
Vitamin D (Cobas ${ }^{\circledR e} 411$, Roche, Germany). Serum $[25(\mathrm{OH})$ D] levels of $20-30 \mathrm{ng} / \mathrm{ml}$ defined vitamin $D$ insufficiency, and a level of $<20 \mathrm{ng} / \mathrm{ml}$ defined vitamin $\mathrm{D}$ deficiency, while levels $>30 \mathrm{ng} / \mathrm{ml}$ defined normal vitamin D level (sufficient) ${ }^{(6)}$. Special investigations included immunoglobulin (IgM, IgG, and IgA): by immunoturbidimetric assay in which Anti-lgM/G/A antibodies react with antigen in the sample to form an antigen/antibody complex (Agglutination) then it was measured turbidimetrically by Cobas ${ }^{\circledR e} 411$, Roche, Germany.

Table 1: Demographic distribution of the studied groups

\begin{tabular}{|l|c|c|c|c|c|}
\hline Variable & $\begin{array}{c}\text { Vitamin D } \\
\text { resistant rickets } \\
(\mathrm{n}=30)\end{array}$ & $\begin{array}{c}\text { Vitamin } \mathrm{D} \\
\text { deficiency rickets } \\
(\mathrm{n}=30)\end{array}$ & $\begin{array}{c}\text { Controls } \\
(\mathrm{n}=30)\end{array}$ & $\begin{array}{c}\text { Statistical } \\
\text { test }\end{array}$ & $p$ \\
\hline Age (years)@ & $4.34 \pm 3.42$ & $5.58 \pm 5.17$ & $4.58 \pm 3.77$ & $1.631(\mathrm{~F})$ & 0.211 \\
\hline Weight (kg)@ & $12.28 \pm 4.09$ & $13.25 \pm 5.29$ & $14.29 \pm 5.67$ & $0.420(\mathrm{~F})$ & 0.661 \\
\hline $\begin{array}{l}\text { Head circum- } \\
\text { ference (cm) }\end{array}$ & $52.81 \pm 1.99$ & $46.67 \pm 1.37$ & $45.66 \pm 1.53$ & $9.411(\mathrm{~F})$ & $\mathbf{0} .001$ \\
\hline $\begin{array}{c}\text { Sex } \\
\text { Female }\end{array}$ & $16(53.3 \%)$ & $18(60 \%)$ & $16(53.3 \%)$ & $2.312(\chi 2)$ & 0.315 \\
\multicolumn{1}{c|}{ Male } & $14(46.7 \%)$ & $12(40 \%)$ & $14(46.7 \%)$ & & \\
\hline $\begin{array}{c}\text { Sun exposure } \\
\text { Good } \\
\text { Unusual }\end{array}$ & $10(33.3 \%)$ & $12(40 \%)$ & $14(46.7 \%)$ & $4.413(\chi 2)$ & 0.353 \\
\hline
\end{tabular}

$@=$ dat $a$ are presented as Mean \pm SD; F= ANOVA analysis of variance; $\chi^{2}=$ chi-square test, $p$-value $\leq 0.05$ : significant; $p>0.05=$ Non-significant

\section{Statistical Analysis}

Data were analyzed by SPSS (Statistical Package for Social Sciences version 20, Chicago, IL, USA). Data were expressed as a mean \pm standard deviation for quantitative variables or number and percentage for categorical variables. Data were tested for normal distribution using the Shapiro Walk test. Qualitative data were represented as frequencies and relative percentages. Chi square test $\left(\chi_{2}\right)$ and Fisher exact was used to calculate difference be- tween qualitative variables as indicated. Quantitative data were expressed as mean SD. One-way ANOVA test was used to compare between more than two dependent groups of normally distributed variables while Friedman's test ranks test was used for non-normally distributed variables. Pearson's and Spearman's correlation tests were used for correlating normal and non-parametric variables, respectively. All statistical comparisons were two tailed with significance Level of $P \leq 0.05$ indicates significant, $\quad p<0.001$ indicates 
highly significant difference while, $\mathrm{P}>0.05$ indicates non-significant difference.

\section{Results}

Our study included 60 patients divided into 2 groups: Group $(A)$ : thirty cases with vitamin $D$ resistant rickets patients $(M / F$ : 14/16) and Group (B): thirty cases with untreated classic vitamin $D$ deficiency rickets (M/F: 12/18). Group (C): thirty healthy subjects as a control group (M/F: 14/16). The demographic data of the three studied groups are shown in (table 1). Significant difference was found between the three studied groups as regard head circumference. However, there was no statistically significant difference between the three studied groups regarding age, sex, weight, or sun exposure. Our result revealed a significant decrease in hemoglobin level in patients with vit. $D$ resistant rickets and those with vit. D deficiency compared to control subjects (table 2 ).

Table 2: Laboratory parameters of the studied groups

\begin{tabular}{|l|c|c|c|c|c|}
\hline Variable & $\begin{array}{c}\text { Vitamin D } \\
\text { resistant } \\
\text { Rickets } \\
(\mathrm{n}=30)\end{array}$ & $\begin{array}{c}\text { Vitamin } \mathrm{D} \\
\text { deficiency } \\
\text { rickets } \\
(\mathrm{n}=30)\end{array}$ & $\begin{array}{c}\text { Controls } \\
(\mathrm{n}=30)\end{array}$ & $F$ & $p$ \\
\hline Hemoglobin(g/dL) & $10.59 \pm 1.69$ & $10.29 \pm 1.45$ & $13.38 \pm 1.99$ & 9.342 & $\mathbf{0 . 0 0 1}$ \\
\hline Total Bilirubin $(\mathrm{mg} / \mathrm{dL})$ & $0.78 \pm 0.17$ & $0.85 \pm 0.46$ & $0.60 \pm 0.15$ & 1.291 & 0.315 \\
\hline Direct Bilirubin $(\mathrm{mg} / \mathrm{dL})$ & $0.89 \pm 0.32$ & $0.92 \pm 0.12$ & $1.05 \pm 0.18$ & 1.413 & 0.284 \\
\hline Albumin(g/dL) & $4.11 \pm 0.84$ & $4.49 \pm 0.60$ & $4.24 \pm 0.17$ & 1.705 & 0.202 \\
\hline Total protein(mg/dL) & $5.84 \pm 0.91$ & $5.96 \pm 1.25$ & $6.91 \pm 0.27$ & 1.615 & 0.242 \\
\hline ALT $(\mathrm{U} / \mathrm{L})$ & $17.04 \pm 5.91$ & $19.32 \pm 5.57$ & $18.77 \pm 1.35$ & 1.459 & 0.299 \\
\hline AST $(\mathrm{U} / \mathrm{L})$ & $30.38 \pm 13.9$ & $38.96 \pm 27.59$ & $27.0 \pm 7.09$ & 1.104 & 0.345 \\
\hline $\mathrm{S} . \mathrm{Creatinine}(\mathrm{mg} / \mathrm{dL})$ & $0.412 \pm 0.30$ & $0.447 \pm 0.22$ & $0.675 \pm 0.21$ & 2.711 & 0.085 \\
\hline $\mathrm{Urea}(\mathrm{mg} / \mathrm{dL})$ & $9.7 \pm 3.42$ & $8.49 \pm 11.73$ & $10 \pm 2.74$ & 0.934 & 0.405 \\
\hline $\mathrm{Na}(\mathrm{mmol} / \mathrm{L})$ & $140.17 \pm 2.37$ & $139.0 \pm 3.53$ & $137.8 \pm 1.75$ & 2.205 & 0.128 \\
\hline $\mathrm{K}(\mathrm{mmol} / \mathrm{L})$ & $3.72 \pm 0.78$ & $3.39 \pm 0.98$ & $3.8 \pm 0.31$ & 0.798 & 0.460 \\
\hline $\mathrm{Mg}(\mathrm{mEq} / \mathrm{L})$ & $1.8 \pm 0.65$ & $1.74 \pm 0.30$ & $1.98 \pm 0.25$ & 0.789 & 0.464 \\
\hline
\end{tabular}

Data are presented as mean $\pm S D ; F=$ ANOVA analysis of variance; $\chi^{2}=$ chi-square test, $p \leq 0.05=$ significant. p $0.05=$ Non-significant

In our study, we found that calcium was significantly decreased in vitamin $D$ resistant patients compared to vitamin $\mathrm{D}$ deficiency patients and control group, while phosphorous was significantly lower in vitamin $D$ deficiency patients and vitamin D resistant patients compared to controls. On the other hand, PTH was significantly higher in vitamin $D$ resistant patients compared to controls and vitamin D deficiency patients. Also, there was a highly significant decrease in vitamin $D$ level in vitamin $\mathrm{D}$ deficiency patients and vitamin $D$ resistance patients groups compared to the controls as shown in (table 3). A significant decrease in IgG level in vitamin $D$ deficiency group compared to vitamin $D$ resistant rickets group and controls were seen. In the meantime, a significant decrease in IgA was observed in vitamin D resistant and vitamin $D$ deficiency patients compared to controls. While no difference in IgM level was observed among the three groups (table 3). There was no significant correlation between immunoglobulin ( $\lg M, \lg G$, and $\lg A)$ and any of studied laboratory parameters in the three studied groups. 
Table 3: Specific bone parameters and immunoglobulins levels of the studied groups

\begin{tabular}{|c|c|c|c|c|c|c|}
\hline Variable & $\begin{array}{c}\text { Vitamin D } \\
\text { resistant } \\
\text { rickets } \\
(n=30)\end{array}$ & $\begin{array}{c}\text { Vitamin D } \\
\text { deficiency } \\
\text { rickets } \\
(n=30)\end{array}$ & $\begin{array}{c}\text { Controls } \\
(n=30)\end{array}$ & $F$ & $p$ & LSD \\
\hline $\mathrm{Ca}(\mathrm{mg} / \mathrm{dL})$ & $7.67 \pm 0.93$ & $8.66 \pm 0.93$ & $9.15 \pm 0.5$ & 4.71 & 0.019 & $\begin{array}{l}0.032^{1} \\
0.016^{2} \\
0.325^{3} \\
\end{array}$ \\
\hline $\mathrm{Po}_{4}(\mathrm{mg} / \mathrm{dL})$ & $2.85 \pm 1.99$ & $2.95 \pm 1.43$ & $4.5 \pm .53$ & 5.83 & 0.010 & $\begin{array}{l}0.525^{1} \\
0.006^{2} \\
0.005^{3}\end{array}$ \\
\hline ALP (U/L) & $432.4 \pm 62.7$ & $399.8 \pm 50.42$ & $261.4 \pm 15.92$ & 5.292 & 0.012 & $\begin{array}{l}0.335^{1} \\
0.001^{2} \\
0.004^{3}\end{array}$ \\
\hline PTH (pg/mL) & $184.4 \pm 46.8$ & $70.28 \pm 12.22$ & $26.7 \pm 7.42$ & 32.13 & $<0.001$ & $\begin{array}{l}0.005^{1} \\
0.001^{2} \\
0.022^{3}\end{array}$ \\
\hline $\operatorname{ESR}(\mathrm{mm} / \mathrm{h})$ & $12.04 \pm 1.5$ & $12.08 \pm 2.41$ & $6.33 \pm 3.16$ & 8.94 & $<0.001$ & $\begin{array}{l}0.928^{1} \\
0.004^{2} \\
0.004^{3}\end{array}$ \\
\hline $\begin{array}{l}\text { Vitamin D } \\
(\mathrm{mg} / \mathrm{dL})\end{array}$ & $22.07 \pm 6.5$ & $15.47 \pm 2.51$ & $35.4 \pm 4.63$ & 17.92 & $<0.001$ & $\begin{array}{l}0.028^{1} \\
0.004^{2} \\
0.001^{3}\end{array}$ \\
\hline $\lg A(\mathrm{mg} / \mathrm{dL})$ & $3.13 \pm 1.7$ & $3.74 \pm .867$ & $5.01 \pm 1.61$ & 5.292 & 0.012 & $\begin{array}{l}0.365^{1} \\
0.004^{2} \\
0.032^{3} \\
\end{array}$ \\
\hline $\operatorname{lgM}(\mathrm{mg} / \mathrm{dL})$ & $3.56 \pm 1.4$ & $3.56 \pm 1.015$ & $4.29 \pm 1.38$ & 1.381 & 0.265 & $\begin{array}{l}0.160^{1} \\
0.998^{2} \\
0.182^{3}\end{array}$ \\
\hline $\operatorname{lgG}(\mathrm{mg} / \mathrm{dL})$ & $751.25 \pm 163.5$ & $523.5 \pm 136.3$ & $692.0 \pm 186.4$ & 8.385 & 0.009 & $\begin{array}{l}0.003^{1} \\
0.036^{2} \\
0.019^{3}\end{array}$ \\
\hline
\end{tabular}

$P 1=$ Vitamin $D$ resistant versus vitamin $D$ deficiency; $P 2=$ Vitamin $D$ resistant versus controls; $P_{3}=$ vitamin $D$ deficiency versus controls; $F=$ ANOVA analysis of variance; $P$-value $\leq 0.05=$ significant; $p<0.001=$ highly significant; $P>0.05=$ Non-significant

\section{Discussion}

Some immune system disorders associated with rickets and vitamin D might play a role in the progress of infection ${ }^{(7)}$. Our result revealed a significant decrease in hemoglobin in vitamin $D$ resistant rickets and vitamin $D$ deficiency groups in comparison to controls. This may be due to the common nutritional and environmental factors or the direct suppression of hepcidin mRNA transcription. This runs with a previous study which concluded that three types of anemia are associated with vitamin $D$ deficiency rickets. The first is iron deficiency anemia due to having common nutritional and other factors, the second is hemolytic anemia known as Northern syndrome that was reported among local American Indians and the third is a very rare anemia due to myelofibrosis with involvement of platelets and neutrophils ${ }^{(8)}$. We found that calcium and phosphorous was significantly decreased 
in vitamin D deficiency patients compared to the control group. This runs with Holick et al.(9) who reported that the serum levels of calcium and phosphorus were significantly lower in the vitamin D deficiency group. The low levels of calcium and phosphate may be explained by the role of vitamin $D$ in their homeostasis. In our study, there was no significant difference between groups in IgM while IgG were found to be significantly decreased in vitamin $\mathrm{D}$ deficiency group compared to vitamin $\mathrm{D}$ resistance group. This runs with Paulino et al. ${ }^{(10)}$ documented that in the group of children with IgG deficiencies, vitamin $D$ concentrations were significantly lower than in other patients without IgG deficiencies, something that was also observed in patients with primary and secondary immunodeficiency. Also, Dąbrowska-Leonik et al.(11) demonstrated that patients with reduced Ig $G$ had statistically-significant lower vitamin D concentrations than children with normal concentrations of $\lg G$ and they found that IgG deficiency does not result from the synthesis-inhibiting effect of vitamin D. Moreover, they showed that vitamin D3 supplementation was needed in patients with reduced IgG levels, and also in the case of associated reduced IgA and IgM concentrations. On the other hand, Chen et al. ${ }^{(12)}$ found that vitamin $D$ inhibits Ig production by inhibiting IL-2 receptor expression on B cells. Also, vitamin D has inhibitory functions on the adaptive immune system by preventing of $B$ cell proliferation and differentiation and therefore reduces immunoglobulin secretion as well as decreased production of inflammatory cytokines ${ }^{(13-14)}$. Another study, by Lemire et al. ${ }^{(15)}$ showed that 1,25-(OH)2-D3 was a potent inhibitor of human peripheral blood mononuclear cells Ig production, especially IgM and IgG in vitro, and suggested that this action was mediated through the hormone's anti-proliferative effect on Ig-producing B cells and/or helper $T$ cells. It is possible that vitamin $D$ not only causes a reduction in immunoglobulins during the activation of the immune system, but also stimulates resting B lymphocytes directly or indirectly through dendritic cells and T lymphocytes to produce immunoglobulins. Moreover, Von Bahr et al.(16) determined that children with higher vitamin D concentrations were more susceptible to have lower IgG concentrations, and required substitution with immunoglobulin preparations. There was a significant decrease of IgA in vitamin $D$ resistant patients and vitamin D deficiency patients' groups as compared to controls. This can lead to recurrent respiratory tract disease. Initially, an association between vitamin $D$ deficiency and respiratory tract infections (RTIs) in children was found after a higher incidence of RTIs was found among infants and children with rickets as reported by Najada et al. ${ }^{(17)}$ who found that vitamin D deficiency was associated with an increased incidence of lower RTIs requiring hospitalization (severe pneumonia). This is because vitamin $D$ may play a role in activating the innate immune system. Gradually, other RTIs in children have also been linked to vitamin D. The evidence that the peak of viral infections is in the winter months when synthesis of vitamin D across the skin is naturally impaired supported the association $^{(18,19)}$.

\section{Conclusion}

Patients with vitamin $D$ deficiency have significant lower IgG levels, while vitamin $D$ resistant patients have significant higher IgG levels. Whereas, both groups have lower IgA and normal IgM levels.

\section{Acknowledgements}

The authors thank the staff of our university children's hospital for their collabora- 
tion as well as the parents of children's who accepted to participate in the study.

\section{References}

1. Creo AL, Thacher TD, Pettifor JM, et al. Nutritional rickets around the world: an update. Paediatr Int Child Health. 2017; 37 (2): 84-98.

2. Wallace E, Day M, Fadare O, et al. Pathologic Femur Fracture Due to a Brown Tumor in a Patient with Secondary Hyperparathyroidism and Vitamin DResistant Rickets. Am J Kidney Dis. 2013; 61(2): 337-341.

3. Hotamisligil GS. Inflammation and metabolic disorders. Nature 2006; 444:860867.

4. Walker VP, Modlin RL. The vitamin D connection to pediatric infections and immune function. Pediatr Res. 2009 May; 65(5Pt 2):106R-113R.

5. Haider N, Nagi AG, Khan KM. Frequency of nutritional rickets in children admitted with severe pneumonia. J Pak Med Assoc 2010 Sep; 60(9):729-732.

6. Holick MF. Vitamin D deficiency. NEJM 2007; 19; 357(3):266-281.

7. Sahay M, Sahay R. Rickets-vitamin D deficiency and dependency. Indian J Endocr Metab 2012; 16:164-176

8. Elidrissy ATH, Zolali MA, Hawsawi Z. Anaemia associated with vitamin $D$ deficiency rickets. Archives of Disease in Childhood 2011; 96:A82.

9. Holick $M$, Binkley $\mathrm{N}$, Bischoff-Ferrari $\mathrm{H}$, Gordon C, Hanley D, Heaney R, et al. Evaluation, treatment, and prevention of vitamin $D$ deficiency: an endocrine society clinical practice guideline. J Clin Endocrinol Metab 2011; 96: 1911-1930.

10. Paulino TL, Rafael MN, da Silva R, dos Santos-Valente EC, et al. Vitamin D and Primary Immunodeficiencies. BJMMR 2015; 7(12): 1035-1038.

11. Dąbrowska-Leonik N, Bernatowska E, Pac M, Filipiuk W, Mulawka J, et al. Vitamin D deficiency in children with recurrent respiratory infections, with or without immunoglobulin deficiency. Adv Med Sci 2018; 63(1):173-178.
12. Chen S, Sims GP, Chen XX, Gu YY, Chen S, Lipsky PE. Modulatory effects of 1,25dihydroxyvitamin D3 on human B cell differentiation. J Immunol 2007; 179: 16341647.

13. Linker-Israeli $M$, Elstner E, Klinenberg JR, Wallace DJ, Koeffler HP. Vitamin D(3) and its synthetic analogs inhibit the spontaneous in vitro immunoglobulin production by SLE-derived PBMC. Clin Immunol 2001; 99(1):82-93.

14. Pincikova T, Nilsson K, Moen IE, et al. Inverse relation between vitamin $\mathrm{D}$ and serum total immunoglobulin $G$ in the Scandinavian Cystic Fibrosis Nutritional Study. Eur J Clin Nutr 2011; 65: 102-109.

15. Lemire JM, Adams JS, Sakai R, Jordan SC. 1 alpha, 25-dihydroxyvitamin D3 suppresses proliferation and immunoglobulin production by normal human peripheral blood mononuclear cells. J Clin Invest $1984 ; 74: 657-661$.

16. von Bahr L, Blennow O, Alm J, Björklund $\mathrm{A}$, Malmberg $\mathrm{KJ}$, et al. Increased incidence of chronic GVHD and CMV disease in patients with vitamin $D$ deficiency before allogeneic stem cell transplantation. Bone Marrow Transplant 2015; 50(9):12171223.

17. Najada AS, Habashneh MS, Khader M. The frequency of nutritional rickets among hospitalized infants and its relation to respiratory diseases. J Trop Pediatr 2004; 50:364-368.

18. Holick MF, Chen TC. Vitamin D deficiency: a worldwide problem with health consequences. Am J Clin Nutr 2008; 87:S10801086.

19. Shaygannejad V, Maljaei MB, Bank SS, Mirmosayyeb O, Maracy MR, Askari G. Association between Sun Exposure, Vitamin D Intake, Serum Vitamin D Level, and Immunoglobulin G Level in Patients with Neuromyelitis Optica Spectrum Disorder. Int J Prev Med 2018; 9:68. 